\title{
Research on the design of The Intelligent Transportation Cycling System \\ based on the Internet of Things technology simulating
}

\author{
Xinyue $X U$ \\ Electronics and Information Engineering School, Anhui University, Hefei, China \\ xuxinyuekelly@163.com
}

\begin{abstract}
Keywords: The Internet of Things, Database Maintain System, RFID, the Intelligent Transportation Cycling System
\end{abstract}

\begin{abstract}
Currently, China's Internet of Things (IoT) industry has developed rapidly. In order to advocate green travel and energy saving, the Intelligent Transportation Cycling System (ITCS) provides strongly favorable conditions for the development of public bicycle. This article introduces the concept of the Internet of Things and various parts of the constructer of the Intelligent Transportation Cycling System based on the Internet of Things technology stimuli. And this article analyzes the function and technique of each part of the Intelligent Transportation Cycling System. Finally, the article discusses the current problems in development and feasibility of the system. The Intelligent Transportation Cycling System will lay the foundation of public transport and green travel in the future.
\end{abstract}

\section{Introduction}

The Internet of Things (IoT) binds things together, creates relationships between one item with another, and includes them in a network through RFID (Radio Frequency Identification) tags, infrared sensors, global positioning systems (GPS), laser scanners and other information-sensing device according to certain agreements. IoT monitors, manages and intelligently identifies things in the network it creates. The International Telecommunication Union defines IoT as the network that connects all objects into a net by information labeling and sensing devices such as RFID (Radio Frequency Identification) tags, infrared sensors, global positioning systems (GPS), and laser scanners, in order to share and exchange information and finally realizes real-time and intelligent management of things in the network.

Nowadays, information technology develops rapidly. IoT has become one of the focuses of global concern and been widely known. It is considered to be one of the largest scientific and technical innovations following the Internet. People are looking forward to that whether the Internet of Things will create a miracle or not. The knowledge area IoT has reached is further than expectation; the influences of its achievement are astonishing.

Since August 2009 Premier Wen Jiabao put forward the "Experience China" Scheme for the first time and listed the Internet of Things as one of the "five emerging strategic industries" and wrote into "Government Work Report", IoT has aroused great concern in China. Since 2012 when 31 universities in China first attempted to establish IoT to the gradual mature of such technology, IoT in China has seen a steady development toward future implementation. In the following decade, it is promising that IoT will help Chinese agriculture, industries, and services climb up to new high. 


\section{The intelligent public traffic situation in China}

By the beginning of 2015, 31 cities have reached over one million cars averagely. In particular, there are more than 5 million cars in Beijing. Domestic car ownership increased from 24 million in 2004 to 137 million in 2015, resulting in tremendous pressure from traffic jam in China. And this trend will not slow down in the short term. Public transport being crowded and slow causes most people choose not to use public transportation, thus the frequency of using private cars remains high. However, the passengers of Beijing underground transportation system every day are around 9 million. The survey found a survey has shown that $40 \%$ passengers go to work by subway because of the long distance between home and work. But other $60 \%$ passengers are forced to take subways for the heavy traffic on the road, though they do not live far from work. The best solution for the current traffic congestion is to introduce a green public transportation method - cycling system, and encourage people to use it. The existing green cycling system however is not preferred by the public because it has not been completed yet; rental and stolen problems happen frequently. The overall experiencing of cycling in the city remains on a low level whereas the cycler's safety is not guaranteed, nor can his needs be satisfied. Thereby, the new design based on IoT proposes that bicycles should be intellectualized, included in the IoT, and installed with functions of recording, guiding, and electricity charging.

\section{The Intelligent Transportation Cycling System structure}

In international contest of innovation iCAN, our team aims to design an intelligent cycling system, and to explore and employ Internet of Things technology to achieve real-time monitoring and management for the intelligent cycling system. Our design offers variable green travel public transportation references for future modeling. But because of technical restriction, our design is limited on functions for only demonstrating the operation.

Perceiving layer: Using EPC, RFID, sensors, readers, intelligent robots and other technology to identify various objects and collect relevant information. The Intelligent Transportation Systems locates the vehicles by RFID tags and GPS system on the bike, in order to collect information.

Network layer: Deliver the information collected through the Internet, and wireless communication network. The Intelligent transportation cycling system transfers information that is received from perceiving layer to the database and makes records.

Processing layer: Analyze and process information in the database through artificial intelligence, cloud computer technology. The Intelligent Transportation Cycling System records and analyzes bicycle rental information. It puts the number of bike rent in inventory and records the information of renter failed to return the bike. And then it analyzes the position data collected by GPS, in order to provide the nearest bike returning point.

Application layer: Implement the results obtained from the processing layer. Inventory the number of bicycles and send messages to bike renters who failed to return the bike.

The Intelligent Cycling Rental Management System. The Intelligent Cycling Rental Management System includes the unified monitoring of bikes and the statistics of bike rentals.

There are many public cycling rental locations in metropolis like Shanghai, however most of them are not been used frequently. In this new design of the Intelligent Cycling Rental System, everyone has the one-card-through that contains a RFID tag including ID, contact information, financial information, etc. When customer swipes the card to rent a bike, corresponding information will be read and transmitted to the data processing center through the Intelligent Rental 
Management System. The system will record the bike's stipulated return time and update to back-end database. System numbers each bike according to the RFID tag. Simultaneously, rental time of the bike, returning time of the bike and other information are also recorded onto the database. When customer returns the bike in any rental location, swipes his card, the bike information in the database will be updated. If the customer has not returned the bike on time, the system will send a notification message to him. If the customer still has not returned the bike after receiving the message in 10 days, the system will transfer the bike owner's information to the local police automatically. Radio Frequency Identification technology and database technology constitute the core technology of the Intelligent Rental Management System, which can greatly reduce the loss of the public bikes.

The Intelligent Global Positioning System (GPS). GPS provides not only accurate navigation function for the riders, but also collects real-time location information. The position information will be transmitted to the controller. The controller will make a comparison between the existing data and real-time location information, then provide surrounding landscape, road traffic and travel suggestions. This feature provides a great convenience for people to enjoy weekend trip. Additionally, GPS will show the nearest rental location of bikes to customer based on comparison results in the database, providing a great convenience.

The Intelligent Fitness System. The Intelligent Fitness System can monitor heart rate, riding speed and air quality. The system will upload personal data, for example weight and height to the database, and give recommendations for the rider, through comparisons between existing data and his new date. The system will also analyze the day's air quality whether it is appropriate for riding a bike or not. And the rider can use Bluetooth to upload daily exercise data to his mobile phone application while riding.

The Intelligent Charging System. Riders can charge the small battery installed on the bike by solar panels to power up the intelligent operating system on the bike. The Intelligent Charging system allows instant charging while riding, and avoids the trouble of wasting time on charging.

\section{The problem of the Intelligent Transportation Cycling System}

Currently, the Internet of Things industry is still in its infancy because of limited technical resources, and the high costs. Current technology cannot fulfill mass production. Green transportation has not been applied widely in the public domestically. The tradition and custom of driving private cars or taking a taxi has caused a hard situation for the Intelligent Transportation Cycling System to popularize.

The Internet of Things industry has just begun; there are no industry standards to restrict the development in different departments currently. It will easily form a certain degree of confusion. Another problem is whether privacy and personal information can be guaranteed or not during information transmission.

\section{Conclusion}

Currently, the increasingly serious traffic pressure and environmental problems has drawn people's attention. People started to pay more attention to the fitness and public bicycle, which will help promote the bicycle as a public transportation. The Intelligent Transportation Cycling System connects each bicycle to a network, and increases public bike's usability and manageability. Now the Intelligent Transportation Cycling System is still in design. If only consider the trend of green traveling, can the prospects for the development of Intelligent Transportation Cycling System be 
broad. However, given that the current domestic Industry of Things has just started and IOT technology is not yet standardized, the maturation process of its development and the riding system will take a long time.

\section{References}

[1]WangXiaojing, ZhangJin. Research on internet of things[J]. Journal of Liaoning University:Natural Sciences Edition,2010,37(1):37-38.

[2] MouLongfang. Future development outlook for internet of things[J]. Information Technology \& Standardization,2010,51(4):48-49.

[3] YeFan. Theoretical explanation of inquiry-based teaching ofcollege science coursed \& practical probea case of college physics course [J]. Theory and Practice of Education,2011(24): 49-51.

[4]HanXue. Research on the design of The Intelligent Campus Systembased on the internet of things technology[J]. Electronic Design Engineering, 2011(24): 41-03

[5]ZhangShunyi,NingXianyan. The research and development of the internet of things network management technology [J]. Journal of Nanjing University of Posts and Telecommunications: Natural Science,2010(4):30-35. 